\title{
Salicylate Metabolism in Twins
}

\section{EVIDENCE SUGGESTING A GENETIC INFLUENCE AND INDUCTION OF SALICYLURATE FORMATION}

\author{
Daniel E. Furst, Niroo Gupta, and Harold E. Paulus \\ From the Department of Medicine, School of Medicine, University of California, Los Angeles, \\ California 90024
}

A B S T R A C T To evaluate the contribution of genetic influences on the individual variation in plateau serum salicylate levels, salicylate metabolism was studied in seven pairs of identical and six pairs of fraternal twins.

Under the conditions of this study, after a single i.v. dose $(40 \mathrm{mg} / \mathrm{kg}$ ) of sodium salicylate, the serum salicylate concentration versus time curve approximated a straight line on linear coordinates (appeared approximately zero order). The slopes of the decay curves ranged between 0.64 and 1.02 . The intrapair variation for identical twin pairs was significantly less than for fraternal twin pairs $(P=0.044)$. Likewise pleateau serum salicylic acid concentrations (milligrams/deciliter) and total salicylic acid excretion rate after multiple doses demonstrated significantly less intrapair variation for identical twins than for fraternal twins $(P=0.043$ and 0.006$)$. Plateau salicylurate excretion (milligram/kilogram per hour) differences after multiple dosing had a $P=0.067$. Michaelis-Menton constant for salicylurate formation and hours to $50 \%$ excretion after the i.v. dose were not different when comparing identical and nonidentical twins.

Salicylurate formation rates were increased after 3 days of oral therapy, and this induction phenomenon may account for much of the apparent discrepancy between genetic influences on salicylurate formation rates observed after single and multiple dose salicylate administration.

This study suggests that the plateau concentration of serum salicylate varies among individuals given the same weight-adjusted dose in part because of geneti-

Dr. Furst's present address is the Department of Medicine, University of California, San Francisco, San Francisco, Calif. 94143 and Dr. Gupta's present address is Endo Laboratories, Inc., Garden City, N. Y. 11530.

Received for publication 6 July 1976 and in revised form 18 March 1977. cally determined variations in their metabolism of salicylate.

\section{INTRODUCTION}

There are large individual differences in the aspirin dosage required to achieve adequate serum salicylate levels for the treatment of rheumatoid arthritis, rheumatic fever, and similar diseases. This is of special clinical importance because intensive salicylate therapy for these disorders requires the use of doses large enough to maintain salicylate concentrations just below the toxic range. Indeed, serious intoxication can result from salicylate administration in the therapeutic-dose range, especially in children $(1,2)$. On the other hand, an inadequate concentration may be the cause of therapeutic failure.

Published reports demonstrate significant individual differences in salicylate elimination rates as well as serum salicylate levels at constant doses (3-7). However, no satisfactory explanation of this individual variability is documented.

Levy and his associates $(8-11)$ and others $(6,12)$ have demonstrated that aspirin metabolism is governed by parallel first-order and Michaelis-Menton kinetics. The excretion of two major metabolites of salicylic acid, viz, salicyluric acid and salicyl phenolic glucuronide is capacity limited in the usual therapeuticdosage range. Thus, the excretion rates of salicyluric acid and of salicyl phenolic glucuronide are limited by the body's capacity to produce these metabolites. It is conceivable that individual differences in the maximal capacities of these pathways of salicylate metabolism could be responsible for intersubject variation of salicylate levels. This study was designed to evaluate the contribution of genetic factors in determining the individual variations in salicylate metabolism. 


\section{METHODS}

Seven pairs of identical twins (four male and three female sets) and seven pairs of fraternal twins (four male-female, two male, and one female set), with ages between 16 and $27 \mathrm{yr}$, volunteered for this study. Twins were accepted sequentially into the study as they volunteered (given that they were normal, see below, and of acceptable age). Informed consent was obtained from all individuals and from their parents where appropriate. Typing of the identical twin volunteers for 26 erythrocyte groups determined that they were identical. In the cases of the fraternal twins, sex and phenotypic differences demonstrated nonidentity; if fraternal twins appeared physically similar, they were also typed for 26 erythrocyte groups to document nonidentity. Copies of the birth certificates were obtained from the fraternal twins as proof of sibship. All were normal healthy individuals as determined by history, complete physical examination, and routine laboratory tests (including serum creatinine, alkaline phosphatase, serum glutamic oxaloacetic-acid-transaminase, serum glutamic pyruvic transaminase, total protein, albumin, and urinalysis) and had normal kidney and liver function. None had received any medication for at least $6 \mathrm{wk}$ before the study except one pair of identical females (S. M. and K. M.) who continued taking birth control pills, containing $1 \mathrm{mg}$ norethindrone and $0.05 \mathrm{mg}$ estrogen. Before the study, four pairs of identical twins and three pairs of fraternal twins lived in the same households, whereas the members of the remaining three pairs of identical and four pairs of nonidentical twins were living in separate homes.

For acute studies, the volunteers were hospitalized in the Clinical Research Center of the University of California at Los Angeles School of Medicine, Los Angeles, Calif., and maintained on a regular diet and water ad lib. Ammonium chloride, in doses of $9-12 \mathrm{~g} /$ day, was given in divided doses every $4 \mathrm{~h}$, skipping the night dose, to maintain the urine $\mathrm{pH}$ in the range of 5.0 or below. Acidification of urine minimizes the $\mathrm{pH}$-dependent excretion of free salicylic acid (13), a variable which we desired to minimize for this study of individual metabolic differences. The subjects received ammonium chloride for $48 \mathrm{~h}$ before hospitalization and for $24 \mathrm{~h}$ of equilibration in the hospital. After this, a single dose of sodium salicylate, $40 \mathrm{mg} / \mathrm{kg}$, was given i.v., followed by frequent timed collections of blood for $48 \mathrm{~h}$ and urine samples for at least 48 and up to $72 \mathrm{~h}$ after the injections. Blood was allowed to clot and serum was separated and immediately frozen for subsequent analysis. The total volume of each urine specimen was measured, and the $\mathrm{pH}$ was determined immediately after voiding; an aliquot was then frozen.

Serum salicylate was assayed by the single extraction method of Stevenson (14). According to this method, $0.5 \mathrm{ml}$ of serum is extracted with a solution of malonic acid in $5 \mathrm{ml}$ butyl ether. The ultraviolet absorption peak at $307 \mathrm{~nm}$ is used for identification and determination of salicylic acid. The absorbance readings obtained in repeated determinations, when standard solutions containing 10 or $20 \mathrm{mg} / \mathrm{dl}$ were treated in the same manner as serum, were within $5 \%$ of the mean value.

Free salicylic acid (FSA), ${ }^{1}$ salicyluric acid (SU), salicylic

${ }^{1}$ Abbreviations used in this paper: FSA, free salicylic acid; $\mathbf{H}$, hereditability; $\boldsymbol{K}_{m}$, Michaelis constant; $r$, intraclass correlation coefficient; $r_{\mathrm{DZ}}$, intraclass correlation coefficient, fraternal twins; $r_{\mathrm{MZ}}$, intraclass correlation coefficient, identical twins; SA, salicylic acid; SAG, salicylic acid glucuronides; SU, salicyluric acid; TSA, total salicylic acid; $V_{m}$, MichaelisMenton constant. acid glucuronides (SAG), as well as total salicylic acid (TSA) in urine, were estimated by the colorimetric method of Levy and Procknal (15). The method consists of: $(a)$ determination of FSA by extraction of the sample with carbon tetrachloride and re-extraction into ferric nitrate reagent solution; (b) determination of absorbance due to both FSA and SU by extraction of the sample with ethylene dichloride and re-extraction into ferric nitrate solution; and (c) determination of TSA (i.e. FSA, SU, and SAG) after complete acid hydrolysis of these metabolites to salicylic acid (SA) followed by step $(a)$. SU content is calculated by the difference between $(a)$ and $(b)$ and SAG content is determined by subtracting FSA and SU values from (c). Absorbance peak was read at $530 \mathrm{~nm}$ using a Beckman DU spectrophotometer (Beckman Instruments, Inc., Fullerton, Calif.). Repeated determinations of standard solutions containing $10 \mathrm{mg}$ of salicyclic acid/100 ml and $50 \mathrm{mg}$ of salicyluric acid/ $100 \mathrm{ml}$, treated in the same manner as urine, showed a coefficient of variation of $4 \%$. Gentisic acid excretion was not determined.

After the acute study, and after at least 3 wk without medication, the same pairs of twins were treated as outpatients with $65 \mathrm{mg} / \mathrm{kg}$ per day of buffered aspirin (Ascriptin, William H. Rorer, Inc., Fort Washington, Pa.) given orally in five divided doses at 4-h intervals, skipping the night dose, concomitantly with ammonium chloride ( $6-8 \mathrm{~g}$ per day) to acidify the urine (kept at a $\mathrm{pH}$ of 5.0). After 3 days of aspirin therapy, the plateau serum salicylate levels and urinary FSA, SU, SAG, and TSA were determined during the second dosing interval on the fourth day as follows: blood and urine samples were collected immediately before and 1,2 , and $3 \mathrm{~h}$ after the last dose and the salicylate contents were determined as in the acute studies.

Data treatment. The maximum velocity of salicylurate formation was determined by plotting the following linearized form of the Michaelis-Menton equation:

$$
\frac{S}{\nu}=\frac{K_{m}}{V_{m}}+\left(\frac{1}{V_{m}}\right) S_{1},
$$

where $S$ is the amount of salicylate in the body, $\nu$ is the excretion rate of salicylurate, $V_{m}$ is the theoretical maximum rate of metabolite formation (amount per unit time), and $K_{m}$ is the apparent in vivo Michaelis constant (here the amount in the body, not concentration) (16). Plots were done using linear regression by the least mean-squares method. The contribution of genetic factors in determining the individual differences was estimated by comparing the variances of the differences between the members of the identical pairs with those of the fraternal pairs. The intrapair variance was determined by the following formula:

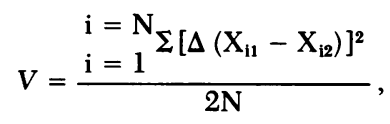

where $X_{11}$ represents one member of a twin pair, $X_{i 2}$ represents the other member, and $N$ is the number of pairs (17). The heritability factor was determined according to the formula:

$$
H=\frac{V_{\mathrm{DZ}}-V_{\mathrm{MZ}}}{V_{\mathrm{DZ}}},
$$

where $V_{\mathrm{DZ}}$ is the variance between members of a dizygotic twin pair and $V_{M Z}$ is the variance between members of a monozygotic twin pair (18). The intraclass correlation co- 


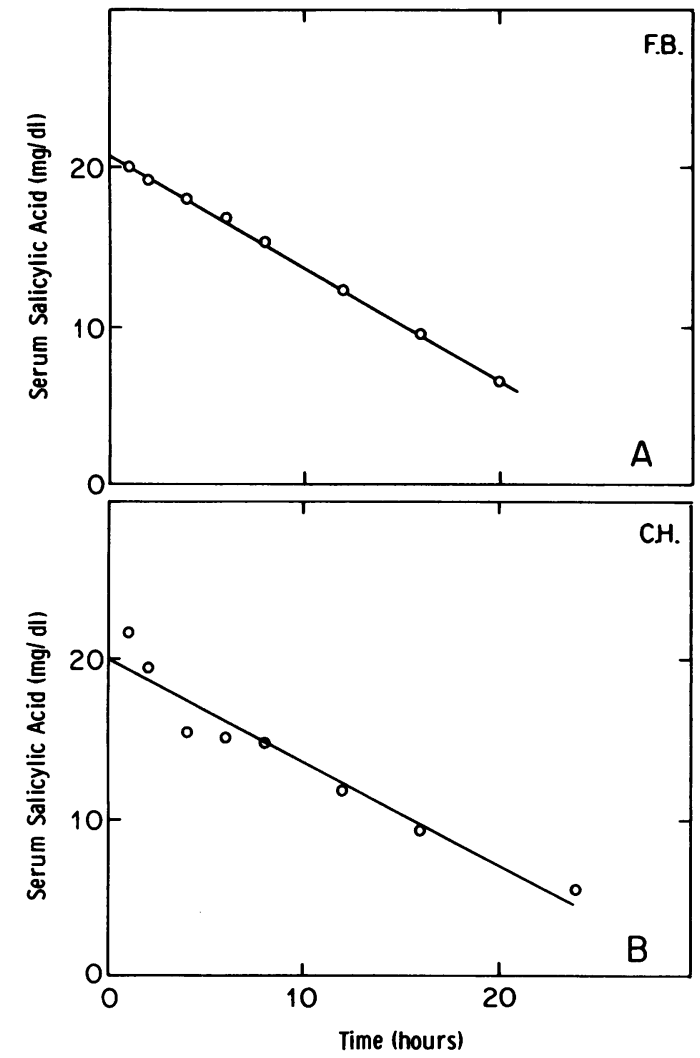

Figure 1 Pseudozero order plots of serum salicylate concentration vs. time after $40 \mathrm{mg} / \mathrm{kg}$ of sodium salicylate i.v. (A) represents the best, and (B) represents the poorest fitting lines for the 26 subjects.

efficient $(r)$ was ascertained by the formula:

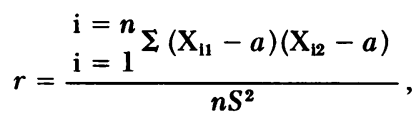

where $X_{11}$ and $X_{i 2}$ are as above, $n$ equals the number of pairs of measurements, $a$ is the mean for the twin measurements of all the twins in one group, and $S^{2}$ is the variance about the mean. Statistical significance was determined by the use of the Mann-Whitney U test or Student's $t$ test. Although twin data are not normally distributed, severely and adversely affecting the usefulness of the $F$ test, it too was calculated, for comparison with the Mann-Whitney $U$ test. The $P$ values were corrected for repeated determinations using the formula $P_{\text {corrected }}=n P(1-P)^{-1}$, where $n$ is the number of variables tested (19). For the i.v. data analysis, $n=4$, whereas $n=3$ for the outpatient data. All values listed in this paper are means \pm SEM unless otherwise noted.

\section{RESULTS}

Acute single-dose (i.v.) study. Plots, using Cartesian coordinates, of the serum concentration versus time data (after a single i.v. dose of $40 \mathrm{mg} / \mathrm{kg}$ sodium salicylate) are shown in Figs. I'A and B. Fig. 1A represents the best fit and Fig. 1B represents the worst fit among the subjects studied. The statistical correlation coefficient for the individual lines, $r$, was greater than 0.990 for 22 of the 26 subjects tested (Table I). The slopes of the linear regression lines ranged from 0.64 to $1.02 \mathrm{mg} / \mathrm{dl} /$ per $\mathrm{h}$ (Table $\mathrm{I}$ ). The summary of the statistical analysis of these data is reported in Table V. The intrapair difference between the slopes was significantly smaller among the identical twins than among the fraternal twins $(P=0.044$, Mann-Whitney $U$ test). Heritability was 0.86 ; the intraclass correlation coefficient among the monozygotic twins $\left(r_{M Z}\right)$ was 0.64 ; among the dizygotic twins, the intraclass correlation coefficient $\left(r_{\mathrm{DZ}}\right)$ was 0.32 .

\section{TABLE I}

Slope of Serum Salicylate Decay Curve (Linear Regression by Least-Square Method) after i.v. Dose of Sodium Salicylate (40 mg/kg), Starting at $2 \mathrm{~h}$

\begin{tabular}{|c|c|c|c|c|c|}
\hline Subject & Sex & Age & Wt & $\begin{array}{c}\text { Decay curve } \\
\text { slope } \pm S E \text { of } \\
\text { estimate }\end{array}$ & $r$ \\
\hline & & $y r$ & kg & $m g / d l / h$ & \\
\hline \multicolumn{6}{|l|}{ Identical twins } \\
\hline Ma. B. & $\mathbf{M}$ & 19 & 69.6 & $0.64 \pm 0.28$ & 0.989 \\
\hline Mi. B. & $\mathbf{M}$ & 19 & 70.0 & $0.65 \pm 0.24$ & 0.992 \\
\hline Le. L. & $\mathbf{F}$ & 17 & 45 & $0.99 \pm 0.09$ & 0.999 \\
\hline Li. L. & $\mathbf{F}$ & 17 & 45.5 & $0.99 \pm 0.28$ & 0.992 \\
\hline L. McC. & $\mathbf{F}$ & 19 & 52.5 & $0.82 \pm 0.21$ & 0.994 \\
\hline M. McC. & $\mathbf{F}$ & 19 & 52.5 & $0.71 \pm 0.24$ & 0.992 \\
\hline S. M. & $\mathbf{F}$ & 25 & 50.4 & $0.77 \pm 0.23$ & 0.993 \\
\hline K. M. & $\mathbf{F}$ & 25 & 48.8 & $0.73 \pm 0.10$ & 0.999 \\
\hline R. P. & $\mathbf{M}$ & 17 & 68.8 & $0.73 \pm 0.24$ & 0.992 \\
\hline H. P. & $\mathbf{M}$ & 17 & 65.0 & $0.74 \pm 0.22$ & 0.993 \\
\hline F. B. & $\mathbf{M}$ & 23 & 67.5 & $0.70 \pm 0.06$ & 0.999 \\
\hline A. B. & $\mathbf{M}$ & 23 & 67.0 & $0.77 \pm 0.12$ & 0.998 \\
\hline R. C. & $\mathbf{M}$ & 19 & 97.0 & $0.61 \pm 0.13$ & 0.997 \\
\hline D. C. & $\mathbf{M}$ & 19 & 92.6 & $0.67 \pm 0.21$ & 0.995 \\
\hline Mean \pm SE & & & & $0.751 \pm 0.03$ & \\
\hline \multicolumn{6}{|l|}{ Fraternal twins } \\
\hline M. B. & $\mathbf{M}$ & 21 & 56.5 & $0.66 \pm 0.39$ & 0.987 \\
\hline S. B. & $\mathbf{F}$ & 21 & 51 & $0.73 \pm 0.36$ & 0.991 \\
\hline W. B. & $\mathbf{M}$ & 20 & 77 & $1.02 \pm 0.17$ & 0.997 \\
\hline B. B. & $\mathbf{F}$ & 20 & 68 & $0.73 \pm 0.46$ & 0.978 \\
\hline E. H. & $\mathbf{F}$ & 27 & 47 & $0.73 \pm 0.27$ & 0.992 \\
\hline C. $\mathrm{H}$. & $\mathbf{F}$ & 27 & 52 & $0.64 \pm 0.49$ & 0.969 \\
\hline D. L. & $\mathbf{M}$ & 22 & 92 & - & 一 \\
\hline J. L. & $\mathbf{M}$ & 22 & 79 & - & - \\
\hline S. McG. & $\mathbf{M}$ & 16 & 65 & $0.86 \pm 0.34$ & 0.991 \\
\hline P. McG. & $\mathbf{F}$ & 16 & 75 & $0.83 \pm 0.42$ & 0.990 \\
\hline Ja. P. & $\mathbf{M}$ & 17 & 68 & $0.85 \pm 0.19$ & 0.995 \\
\hline Ji. P. & $\mathbf{F}$ & 17 & 57 & $0.99 \pm 0.11$ & 0.999 \\
\hline K. W. & $\mathbf{M}$ & 23 & 65 & $0.88 \pm 0.36$ & 0.991 \\
\hline M. W. & $\mathbf{M}$ & 23 & 76 & $0.98 \pm 0.36$ & 0.993 \\
\hline Mean \pm SE & & & & $0.825 \pm 0.04$ & \\
\hline Overall mean & - & 20.4 & 65.0 & 0.785 & - \\
\hline SE & - & 0.8 & 3.73 & 0.02 & - \\
\hline$P($ corrected $)$ & - & $>0.5$ & $>0.5$ & 0.044 & 一 \\
\hline
\end{tabular}


Table II shows the urinary excretion of salicylic acid and its metabolites during the $72 \mathrm{~h}$ after the i.v. injection of sodium salicylate. The mean amount of the total salicylate excreted for all the subjects during this period was $86.3 \pm 2.1 \%$ of the injected dose (range: $62.1-103.3 \%$ ). Of this, $67.5 \pm 1.5 \%$ was excreted as SU, $30.3 \pm 1.3 \%$ as SAG, and the rest as FSA $(3.4 \pm 0.42 \%)$. Ranges for each of the above, as well as the percent excreted by each member of the two groups of twins, may be found in Table II. The SU excretion rate after the single i.v. dose is more or less constant during the first $16-20 \mathrm{~h}$ and then declines in an exponential fashion. This mean maximum observed, sustained SU excretion rate (Table III) was $0.92 \pm 0.02 \mathrm{mg} / \mathrm{kg}$ per $\mathrm{h}$ for the identical twins and $0.91 \pm 0.03 \mathrm{mg} / \mathrm{kg}$ per $\mathrm{h}$ for the fraternal twins $(P>0.5$, Student's $t$ test). Extimations of the Michaelis-Menton constant, $V_{m}$, were calculated from Eq. 1. Plots of the best and worst fit to this equation are shown in Fig. 2. The mean $V_{m}$ for $S U$ was $66.3 \pm 4.1 \mathrm{mg} / \mathrm{h}$ for the identical twins and $64.7 \pm 5.5 \mathrm{mg} / \mathrm{h}$ for the fraternal twins $(P>0.5)$. The SE of the estimates for the individual $V_{m}$ 's, as well as correlation coefficients, may be found in Table III. The time required to excrete $50 \%$ of the total injected dose of $40 \mathrm{mg} / \mathbf{k g}$, determined from cumulative excretion curves, was $15.2 \pm 0.7 \mathrm{~h}$ for the monozygotic twins and $13.9 \pm 0.6 \mathrm{~h}$ for the dizygotic twins $(P>0.5)$. Ranges are seen in Table II.

TABLE II

Urinary Excretion of Salicylates during $72 \mathrm{~h}$ after Sodium Salicylate (40 mg/kg) Given i.v.

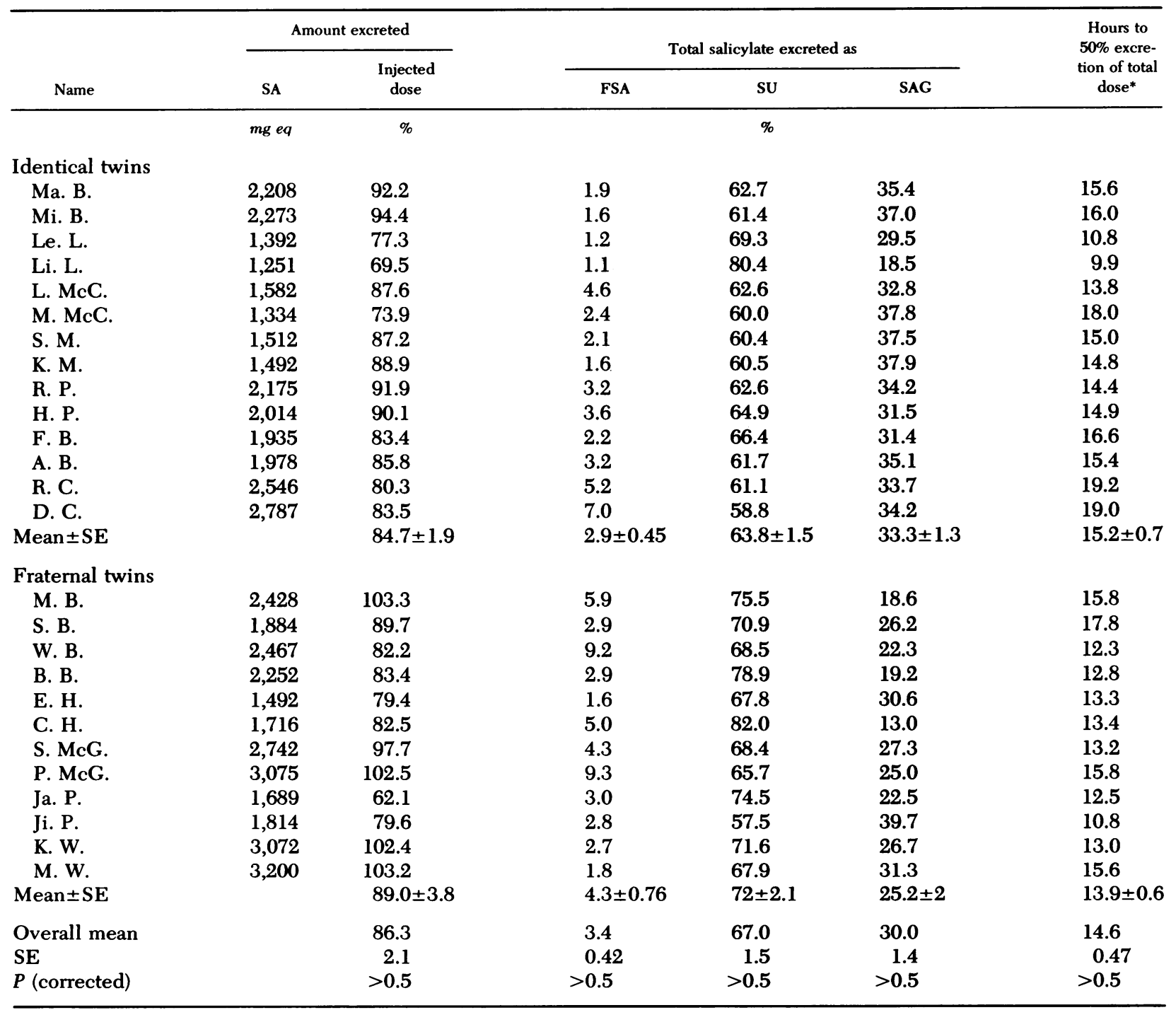

* Computed from total cumulative excretion vs. time curve. 
TABLE III

Urinary Excretion of Salicylurate during $72 \mathrm{~h}$ after Sodium Salicylate $(40 \mathrm{mg} / \mathrm{kg})$ i.v.

\begin{tabular}{|c|c|c|c|c|c|}
\hline \multirow[b]{2}{*}{ Name } & \multicolumn{2}{|c|}{$\begin{array}{l}\text { Maximum observed sustained } \\
\text { SU excretion rate }\end{array}$} & \multirow[b]{2}{*}{$V_{m} \mathrm{SU}$} & \multirow[b]{2}{*}{ SE of estimate } & \multirow[b]{2}{*}{$r$} \\
\hline & $\mathrm{mg} / \mathrm{h} \pm \mathrm{SE}$ & $\mathrm{mg} / \mathrm{kg} / \mathrm{h}$ & & & \\
\hline & & & $m g / h$ & & \\
\hline \multicolumn{6}{|c|}{ Identical twins } \\
\hline Ma. B. & $63 \pm 0.21$ & 0.905 & 64.5 & \pm 1.98 & 0.998 \\
\hline Mi. B. & $64 \pm 2.2$ & 0.911 & 82.0 & \pm 4.86 & 0.980 \\
\hline Le. L. & $45 \pm 2.0$ & 0.999 & 44.2 & \pm 2.95 & 0.994 \\
\hline Li. L. & $50 \pm 2.5$ & 1.11 & 62.5 & \pm 3.09 & 0.988 \\
\hline L. McC. & $51 \pm 1.9$ & 0.973 & 59.7 & \pm 2.35 & 0.996 \\
\hline M. McC. & $40 \pm 1.8$ & 0.762 & 48.3 & \pm 2.56 & 0.994 \\
\hline S. M. & $44 \pm 0.6$ & 0.867 & 50.4 & \pm 2.88 & 0.994 \\
\hline K. M. & $43 \pm 0.6$ & 0.887 & 45.8 & \pm 4.34 & 0.990 \\
\hline R. P. & $67 \pm 1.4$ & 0.966 & 78.7 & \pm 2.97 & 0.992 \\
\hline H. P. & $62 \pm 1.0$ & 0.957 & 68.5 & \pm 2.38 & 0.996 \\
\hline F. B. & $65 \pm 5.2$ & 0.963 & 75.3 & \pm 3.09 & 0.991 \\
\hline A. B. & $63 \pm 0.9$ & 0.937 & 72.1 & \pm 2.93 & 0.994 \\
\hline R. C. & $76 \pm 1.8$ & 0.820 & 93 & \pm 4.34 & 0.987 \\
\hline D. C. & $76 \pm 2.7$ & 0.788 & 84 & \pm 9.15 & 0.960 \\
\hline Mean \pm SE & $58 \pm 3.2$ & $0.918 \pm 0.02$ & $66.3 \pm 4.1$ & & \\
\hline \multicolumn{6}{|c|}{ Fraternal twins } \\
\hline M. B. & $56 \pm 2.5$ & 0.988 & 56.7 & \pm 4.08 & 0.994 \\
\hline S. B. & $40 \pm 4.0$ & 0.782 & 41.9 & \pm 12.4 & 0.976 \\
\hline W. B. & $84 \pm 3.7$ & 1.09 & 92.2 & \pm 5.41 & 0.988 \\
\hline B. B. & $67 \pm 3.1$ & 0.980 & 80.1 & \pm 2.14 & 0.997 \\
\hline E. H. & $40 \pm 1.2$ & 0.852 & 45.0 & \pm 5.61 & 0.992 \\
\hline C. $\mathrm{H}$. & $46 \pm 2.0$ & 0.885 & 60.2 & \pm 3.86 & 0.990 \\
\hline S. McG. & $65 \pm 3.6$ & 0.992 & 63.2 & \pm 5.85 & 0.992 \\
\hline P. McG. & $60 \pm 1.6$ & 0.797 & 67.3 & \pm 4.75 & 0.989 \\
\hline Ja. P. & $50 \pm 1.5$ & 0.731 & 49.8 & \pm 8.52 & 0.990 \\
\hline Ji. P. & $51 \pm 5.7$ & 0.889 & 41.8 & \pm 4.05 & 0.990 \\
\hline K. W. & $74 \pm 4.2$ & 0.989 & 85.7 & \pm 5.68 & 0.981 \\
\hline M. W. & $76 \pm 4.9$ & 0.997 & 92.5 & \pm 10.7 & 0.963 \\
\hline Mean $\pm S E$ & $58 \pm 4.1$ & $0.914 \pm 0.03$ & $64.7 \pm 3.5$ & & \\
\hline
\end{tabular}

Table $\mathrm{V}$ shows the results of the Mann-Whitney $\mathrm{U}$ test, testing intrapair differences among monozygotic twins as compared to intrapair differences among dizygotic twins. It also shows heritability (calculated according to equations 2 and 3) for $\mathrm{SU}$ and total salicylate excretion and appropriate intraclass correlation coefficients (Eq. 4). After the i.v. dose, the intrapair differences for monozygotic twins were not significantly smaller than for the dizygotic twins with respect to the maximum observed sustained SU excretion rate $(P=0.53)$. The $P$ value for the $V_{m}$ of $S U$ was greater than 0.5 , and the $P$ value for the estimation of the hours to $50 \%$ excretion of the total salicylate dose was 0.29 .

Oral multiple-dose treatment. Table IV shows serum salicylate levels and the urinary excretion rate of SU and of TSA after the twins were treated with $72 \mathrm{~h}$ of oral aspirin therapy $(65 \mathrm{mg} / \mathrm{kg}$ per day).
Although we realize that these subjects were not yet at steady state, they were approaching plateau and, as can be seen from the data in Table IV, serum levels were relatively constant over the period of outpatient sampling $(27.7 \pm 1.0 \mathrm{mg} / \mathrm{dl}$ for the identical twins; 22.9 $\pm 1.8 \mathrm{mg} / \mathrm{dl}$ for the fraternal twins). The mean serum salicylate levels, SU excretion rates, and TSA excretion after multiple doses of aspirin were not statistically different when comparing the identical and fraternal twins ( $P>0.1,0.5$, and 0.5 , respectively) (Table IV).

The intrapair differences between the multiple-dose serum salicylate levels for the identical twins were significantly smaller than for the dizygotic twins ( $P$ $=0.04$ ). For $\mathrm{SU}$ excretion, the identical vs. nonidentical twin differences had a probability of 0.067 . The intrapair differences between the identical twins were significantly smaller than those between the fraternal twins for TSA excretion $(P=0.006)$. The heritability 
and intraclass correlation coefficients for all of the above substances are listed in Table $\mathrm{V}$.

It is of interest that the SU excretion rate in milligrams/kilogram per hour in the oral multiple-dose treatment increased by a mean of $50.5 \pm 5.1 \%$ (range: 9-96\%) when compared to the single i.v. dose SU excretion rate in milligrams/kilogram per hour (Tables III and IV).

Although there were seven pairs of identical and seven pairs of fraternal twins entered in the study, one pair of fraternal twins was given an incorrect dose of salicylate i.v. A different set of fraternal twins apparently misunderstood the instructions for the multiple-dose study, and took only $300 \mathrm{mg} /$ day, thus invalidating their results for this portion of the study. Therefore, only six sets of fraternal twins were analyzed in each portion of the study.

Since there were four male-female sets of dizygotic twins, it was possible that sex differences might have led to some systematic bias in the results. This possibility was tested by looking at all the males versus all the females and ascertaining if any statistically significant differences occurred between these two groups. When all the parameters tested in Table V (Statistical Summary) were compared in this way, there were no significant differences found between males and females except in the $V_{m}$. Here there was no normalization of weights, since $V_{m}$ is in $\mathrm{mg} / \mathrm{h}$, and it would not be surprising to find a difference. Even here, when looking at the actual population where bias might occur (the fraternal twins), there was no significant difference found $(P=0.12)$.

\section{DISCUSSION}

This study in identical and fraternal twins suggests that some aspects of salicylate metabolism are genetically determined. Other drugs have set some precedent for this finding. Significant interindividual differences in steady-state plasma levels and biological half-lives of antipyrine $(20,21)$, alcohol (22), phenylbutazone (23), dicumarol (24), nortriptyline (25), and isoniazid (26) have been demonstrated and attributed to genetically determined differences in drug metabolism.

A commonly used twin method for determining the contribution of genetic versus environmental factors employs a comparison of mean monozygotic and mean dizygotic variance observed in two groups of twins $(18,27)$. This method was used here to compute heritability and intraclass correlation coefficients. Although heritability $(\mathrm{H})$ may appear to quantitate genetic influence, used alone it may be misleading, and it is useful to look at the intraclass correlation coefficient $(r)$ at the same time. According to Neel and Schull, $r$ is a ". . . linear function of the ratio of two variances - the variance between members of a twin-

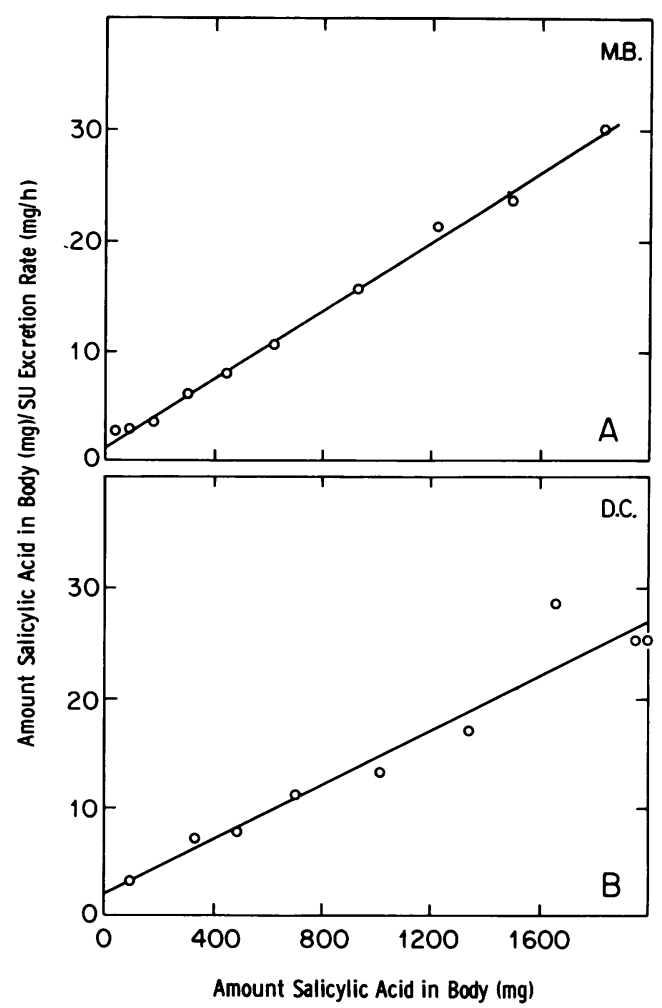

Figure 2 Plot of best (A) and poorest (B) fitting lines depicting data used to calculate $V_{m}$. (Amount of salicylic acid in body/excretion rate of SU vs. amount of salicylic acid in body).

pair and the variance over the whole set of observations ..." (27). They suggest that comparison of $r_{\mathrm{MZ}}$ to $r_{\mathrm{DZ}}$ is the best comparison to appraise the relative contribution of genetic and environmental effects. Thus, the higher the $r$, the less difference exists between twin pairs, and the lower the $r$, the more the difference. Similar $r$ 's indicate lack of large differences between sets of twins despite apparently large $\mathrm{H}$.

As groups, the identical and fraternal twins were not significantly different with respect to age, weight, domicile, TSA, FSA, SU, and SAG excretion, or serum salicylate concentrations, indicating that both groups of twins are members of the same population with respect to these factors.

Serum salicylate concentration was plotted versus time. From Fig. 1, one can see that a linear relationship seems to exist, although Levy (10) showed that the decline of serum sodium salicylate over the range of this study (approximately $30-5 \mathrm{mg} / \mathrm{dl}$ ) is described by parallel first-order and Michaelis-Menton kinetics, which results in a curvilinear plot. FSA, salicyl acyl glucuronide, and gentisic acid excretion follow firstorder kinetics, whereas, salicylurate and salicyl phenol glucuronide excretion follow Michaelis-Menton kinetics (10). In the present study, FSA was kept to a 
TABLE IV

Plateau Serum Salicylate Levels and Urinary Excretion Rates of SU and TSA after 72 h of Oral Aspirin (65 mg/kg/day)

\begin{tabular}{|c|c|c|c|c|c|c|}
\hline \multirow[b]{2}{*}{ Name } & \multirow[b]{2}{*}{$\begin{array}{c}\text { Serum levels, } \\
\text { mean } \pm S E\end{array}$} & \multicolumn{3}{|c|}{ SU excretion rate } & \multicolumn{2}{|c|}{ TSA excretion rate } \\
\hline & & $\begin{array}{c}\mathrm{mg} / \mathrm{h}, \\
\text { mean } \pm \mathrm{SE}\end{array}$ & $\mathrm{mg} / \mathrm{kg} / \mathrm{h}$ & Increase* & $\begin{array}{c}\mathrm{mg} / \mathrm{h}, \\
\text { mean } \pm \mathrm{SE}\end{array}$ & $\mathbf{m g} / \mathbf{k g} / \mathbf{h}$ \\
\hline & $m g / d l$ & & & $\%$ & & \\
\hline \multicolumn{7}{|c|}{ Identical twins } \\
\hline Ma. B. & $25.1 \pm 0.5$ & $97.3 \pm 3.5$ & 1.40 & 54.5 & $104.5 \pm 6.3$ & 1.50 \\
\hline Mi. B. & $27.8 \pm 0.6$ & $99.3 \pm 2.4$ & 1.42 & 55.7 & $109.7 \pm 3.3$ & 1.57 \\
\hline Le. L. & $24.5 \pm 0.2$ & $67.4 \pm 1.6$ & 1.49 & 49.1 & $89.9 \pm 10.1$ & 1.99 \\
\hline Li. L. & $26.0 \pm 0.3$ & $70.4 \pm 3.7$ & 1.54 & 38.7 & $86.4 \pm 2.9$ & 1.89 \\
\hline L. McC. & $25.7 \pm 0.5$ & $78.7 \pm 4.1$ & 1.50 & 54.1 & $110.4 \pm 2.5$ & 2.10 \\
\hline M. McC. & $25.8 \pm 0.8$ & $78.2 \pm 5.3$ & 1.49 & 96.6 & $107.2 \pm 4.1$ & 2.04 \\
\hline S. M. & $26.2 \pm 0.2$ & $72.4 \pm 0.4$ & 1.44 & 65.6 & $83.6 \pm 5.5$ & 1.65 \\
\hline K. M. & $26.6 \pm 0.2$ & $71.1 \pm 2.0$ & 1.46 & 64.2 & $85.0 \pm 5.4$ & 1.71 \\
\hline R. P. & $31.1 \pm 1.0$ & $81.4 \pm 2.6$ & 1.18 & 22.3 & $105.8 \pm 3.9$ & 1.54 \\
\hline H. P. & $29.7 \pm 0.8$ & $78.1 \pm 4.0$ & 1.20 & 26.6 & $116.7 \pm 3.7$ & 1.80 \\
\hline F. B. & $25.4 \pm 0.6$ & $105.3 \pm 1.2$ & 1.56 & 62.1 & $123.9 \pm 2.8$ & 1.75 \\
\hline A. B. & $25.2 \pm 0.2$ & $108.9 \pm 2.2$ & 1.63 & 73.3 & $124.1 \pm 2.6$ & 1.72 \\
\hline R. C. & $36.4 \pm 0.4$ & $102.9 \pm 8$ & 1.11 & 34.6 & $137.2 \pm 0.7$ & 1.48 \\
\hline D. C. & $35.1 \pm 0.5$ & $99.3 \pm 6.4$ & 1.02 & 30.8 & $145 \pm 11.1$ & 1.50 \\
\hline Mean \pm SE & $27.7 \pm 1.0$ & $86.5 \pm 4.0$ & $1.39 \pm 0.05$ & $52.0 \pm 5.4$ & $109.2 \pm 5.1$ & $1.73 \pm 0.6$ \\
\hline \multicolumn{7}{|c|}{ Fraternal twins } \\
\hline M. B. & $17.3 \pm 0.9$ & $78.1 \pm 7.0$ & 1.43 & 44.7 & $82.7 \pm 3.0$ & 1.51 \\
\hline S. B. & $16.9 \pm 1.7$ & $76.7 \pm 7.6$ & 1.48 & 90.5 & $93.3 \pm 7.4$ & 1.80 \\
\hline W. B. & $27.0 \pm 0.88$ & $147.7 \pm 7.9$ & 1.91 & 75.2 & $133.1 \pm 4.2$ & 1.72 \\
\hline B. B. & $31.4 \pm 0.71$ & $121.1 \pm 11.2$ & 1.78 & 81.6 & $135.9 \pm 4.1$ & 2.00 \\
\hline E. $\mathbf{H}$. & $34.3 \pm 0.15$ & $64.6 \pm 8.8$ & 1.38 & 62.0 & $81 \pm 10.2$ & 1.73 \\
\hline C. $\mathrm{H}$. & $22.0 \pm 0.05$ & $76.6 \pm 4.5$ & 1.47 & 66.1 & $73.4 \pm 6.6$ & 1.41 \\
\hline D. L. & $19.4 \pm 0.40$ & $77.5 \pm 7.4$ & 0.84 & - & $110.5 \pm 6.7$ & 1.20 \\
\hline J. L. & $22.8 \pm 0.47$ & $91.3 \pm 9.9$ & 1.15 & - & $115.4 \pm 11.8$ & 1.46 \\
\hline S. McG. & $23.9 \pm 0.24$ & $73.6 \pm 10.6$ & 1.13 & 13.9 & $100.6 \pm 10.5$ & 1.54 \\
\hline P. McG. & $25.8 \pm 0.31$ & $68.4 \pm 7.9$ & 0.91 & 14.2 & $89.9 \pm 9.7$ & 1.19 \\
\hline K. W. & $21.6 \pm 0.41$ & $92.5 \pm 6.3$ & 1.26 & 27.4 & $113.2 \pm 5.9$ & 1.55 \\
\hline M. W. & $11.9 \pm 0.48$ & $82.4 \pm 17.4$ & 1.09 & 9.3 & $83 \pm 17.6$ & 1.10 \\
\hline Mean \pm SE & $22.9 \pm 1.8$ & $87.5 \pm 6.9$ & $1.32 \pm 0.09$ & $48.5 \pm 9.7$ & $101 \pm 6.0$ & $1.52 \pm 0.8$ \\
\hline
\end{tabular}

* Compared to single i.v. dose (Table III).

minimum by ammonium chloride administration (Table II). Gentistic acid is generally only a few percent of the total, leaving only one significant first-order process (salicyl acyl glucuronide formation) (10). Thus, making a linear plot on Cartesian coordinates would be a reasonable first approximation. When plotting serum salicylate concentration versus time after a single i.v. dose of sodium salicylate, the intrapair differences in slopes of the serum salicylate decay curves were significantly smaller between identical twins than between nonidentical twins $(P<0.04$, Table V). Further, after 3 days of oral multiple-dose aspirin therapy, the intrapair variations in salicylate levels and total salicylate excretion rates were also significantly smaller between identical twins than between fraternal twins (Table V). These observations indicate an important genetic influence in determining individual variations in salicylate metabolism.
It is realized that the statistical analysis of twin studies often uses the $F$ test. However, the $F$ test is a parametric test and requires a normally distributed population for correct and optimum usage: Zar states that the $F$ test ". . . is severely and adversely affected by sampling non-normal populations" (28). There is no assurance that twins are normally distributed and, in fact, Kempthorne and Osborne give a number of reasons that twins are not a normally distributed population (17). For this reason, the nonparametric Mann-Whitney U Test was used for most of the analysis in this paper. Nevertheless, for comparison, the $F$ test also was calculated. $F$ values, and the within-dizygotic twin mean squares and within-monozygotic twin mean squares are shown in Table VI. Only two of the seven variables tested were significantly different using the $F$ test (and uncorrected $P$ values). After correction of $P$ values, only one variable remained 
significantly different, illustrating the decrease in sensitivity and power when the $F$ test is used to measure non-normally distributed populations.

Since salicylurate comprised the majority of the salicylate metabolites excreted in this study (67.5 $\pm 1.5 \%$ ), it was expected that it, too, would demonstrate a genetic influence. During the acute study, we could demonstrate no such influence when examining the $V_{m}(H=0.27)$, or the maximum observed salicylurate excretion rate $(\mathrm{H}=0.03)$ (Table V). It should be noted at this point that the $V_{m}$ 's for $S U$ in our 26 subjects $(65.6 \pm 3.3 \mathrm{mg} / \mathrm{h})$ agreed with the values obtained by Levy et al. (11) in his four male normals $(60.3 \pm 3.1 \mathrm{mg} / \mathrm{h})$. Evaluation of the $K_{m}$ requires practically complete recovery of the dose for accurate determination, and since our recovery averaged $86 \%$ we did not include the $K_{m}$ 's in our analysis.

Upon measuring the $\mathrm{SU}$ excretion rate after 3 days of oral therapy, we found smaller differences between identical than fraternal twins with a $P=0.067$ (Table V). $\mathrm{H}$ appeared to be significant $(0.89)$ whereas the $r$ 's were only 0.18 apart $\left(r_{\mathrm{MZ}}=0.94 ; r_{\mathrm{DZ}}=0.76\right)$. Thus, there were indications of genetic influence during the 3-day oral study but not during acute i.v. dose study. Part of the explanation for this apparent inconsistency may lie in another surprising finding; the maximum observed sustained SU excretion rates after 3 days of aspirin therapy were $50.5 \pm 5.1 \%$ greater than those observed during the initial single i.v. dose of sodium salicylate. Even though SU excretion is capacity limited, one could object that the dose of salicylate given was larger during the outpatient portion of the study, so one would expect SU excretion to rise. It is, in fact, true that on a mole for mole basis, there was a $44.4 \%$ increase in dose during the outpatient study. However, this would only be expected to cause a change in $\mathrm{SU}$ excretion from the mean observed maximum SU excretion of $58.0 \mathrm{mg} / \mathrm{h}$ to one no higher than $59.7 \mathrm{mg} / \mathrm{h}$ (see Appendix A); instead the observed plateau SU excretion rate was $87.0 \mathrm{mg} / \mathrm{h}$ (Table IV). Since SU excretion is capacity limited, the only reasonable explanation is an increase in the capacity for SU formation, i.e., induction of glycine synthetase, the enzyme responsible for SU formation. Induction of SU production has not been previously demonstrated. It appeared to occur quickly (over a 3-day period) compared to meprobamate and phenylbutazone which takes weeks to months, but induction of enzymes metabolizing polycyclic hydrocarbons has been documented within $3-6 \mathrm{~h}$ in rats $(21,29,30)$. Further support for this finding comes from Muller et al. who showed falling serum levels of salicylate over time while his subjects were taking a constant dose of aspirin (31). It should be noted that all subjects were specifically asked about recent ingestion of aspirin or salicylate-containing drugs, and denied
TABLE V

Statistical Summary

\begin{tabular}{|c|c|c|c|c|c|}
\hline & \multicolumn{2}{|c|}{ Mann-Whitney 2-tailed U test } & \multirow[b]{2}{*}{ H } & \multirow[b]{2}{*}{$r_{\mathrm{MZ}}$} & \multirow[b]{2}{*}{$r_{\mathrm{D} \%}$} \\
\hline & Uncorrected & Corrected & & & \\
\hline \multicolumn{6}{|c|}{$P$} \\
\hline $\begin{array}{l}\text { Slope of serum sa- } \\
\text { licylate decay } \\
\text { curve, i.v. dose } \\
(40 \mathrm{mg} / \mathrm{kg}) \mathrm{mg} / \mathrm{dl}\end{array}$ & 0.011 & 0.044 & 0.86 & 0.64 & 0.32 \\
\hline $\begin{array}{l}\text { Maximum salic- } \\
\text { ylurate excretion } \\
\text { rate, } \mathrm{mg} / \mathrm{kg} / \mathrm{h}\end{array}$ & 0.144 & 0.534 & 0.03 & - & - \\
\hline$V_{m}, \mathrm{mg} / \mathrm{h}$ & 0.157 & 0.628 & 0.27 & - & - \\
\hline $\begin{array}{l}\text { Hours to } 50 \% \text { ex- } \\
\text { cretion of total } \\
\text { dose }\end{array}$ & 0.074 & 0.294 & 0.38 & - & - \\
\hline $\begin{array}{l}\text { Plateau salicylic } \\
\text { acid (mg/dl) in } \\
\text { serum after } 72 \mathrm{~h} \\
\text { oral dosing } \\
(65 \mathrm{mg} / \mathrm{kg} / \text { day })\end{array}$ & 0.014 & 0.043 & 0.98 & 0.90 & 0.33 \\
\hline $\begin{array}{l}\text { Salicylurate ex- } \\
\text { cretion rate } \\
\text { (plateau) in mg/ } \\
\mathrm{kg} / \mathrm{h} \text { after } 72 \mathrm{~h} \\
\text { oral dosing }\end{array}$ & 0.022 & 0.067 & 0.89 & 0.94 & 0.76 \\
\hline $\begin{array}{c}\text { TSA excretion rate } \\
\text { in } \mathrm{mg} / \mathrm{kg} / \mathrm{h} \text { after } \\
72 \mathrm{~h} \text { oral dosing }\end{array}$ & 0.002 & 0.006 & 0.83 & 0.70 & 0.10 \\
\hline
\end{tabular}

their use. Since, however, salicylates are so widely used and frequently are not identified as such, it is possible that some unintentional exposure to them had occurred in some of the volunteers. Therefore, if partial enzyme induction had occurred in some of them before the i.v. study, intrapair differences might have been magnified for the acute i.v. study, making it difficult to separate identical and fraternal twins. After uniform induction with high-dose oral therapy, however, these genetic differences might again have manifested themselves, hence no statistically significant differences, low $\mathbf{H}$, and $r$ 's during the i.v. study, but statistically significant differences and higher $\mathrm{H}$ during the longer study (Table $\mathrm{V}$ ).

Besides the previous exposure to salicylates, the metabolism of drugs may be influenced by other environmental factors (32). For salicylates, the excretion of one of the important metabolites, FSA, is known to be dependent on urinary $\mathrm{pH}$ (13). In the present study, FSA excretion was almost completely prevented by the administration of ammonium chloride to acidify the urine. Other factors which might help explain 
TABLE VI

Analysis of Results Using the F Test for Comparison to the Mann-Whitney U Test

\begin{tabular}{|c|c|c|c|c|c|}
\hline & \multirow{2}{*}{$\begin{array}{l}\text { Within } \mathrm{DZ}^{*} \\
\text { mean square }\end{array}$} & \multirow[b]{2}{*}{$\begin{array}{l}\text { Within MZt } \\
\text { mean square }\end{array}$} & \multirow[b]{2}{*}{$F \S$} & \multicolumn{2}{|c|}{$P$} \\
\hline & & & & Uncorrected & Corrected \\
\hline $\begin{array}{l}\text { Slope of serum salicylate decay } \\
\text { curve, i.v. dose }(40 \mathrm{mg} / \mathrm{kg}) \mathrm{mg} / \mathrm{dl}\end{array}$ & 0.0184 & 0.0019 & 9.8085 & $<0.05$ & $<0.20$ \\
\hline $\begin{array}{l}\text { Maximum observed SU excretion } \\
\text { rate }(\mathrm{mg} / \mathrm{kg} / \mathrm{h})\end{array}$ & 0.0206 & 0.0096 & 0.7207 & $>0.50$ & $>0.5$ \\
\hline$V_{m}(\mathrm{mg} / \mathrm{h})$ & 19.0 & 33.167 & 0.5723 & $>0.50$ & $>0.5$ \\
\hline $\begin{array}{l}\text { Hours to } 50 \% \text { excretion of } \\
\text { total dose }\end{array}$ & 1.14 & 2.993 & 0.3813 & $>0.50$ & $>0.5$ \\
\hline $\begin{array}{l}\text { Plateau salicylic acid }(\mathrm{mg} / \mathrm{dl}) \text { in } \\
\text { serum after } 72 \mathrm{~h} \text { oral dosing } \\
(65 \mathrm{mg} / \mathrm{kg} / \text { day })\end{array}$ & 21.682 & 0.3295 & 65.7987 & $<0.001$ & $<0.003$ \\
\hline $\begin{array}{l}\text { SU excretion rate (plateau) in } \\
\mathrm{mg} / \mathrm{kg} / \mathrm{h} \text { after } 72 \mathrm{~h} \text { oral dosing }\end{array}$ & 0.0088 & 0.0024 & 3.7262 & $>0.20$ & $>0.5$ \\
\hline $\begin{array}{l}\text { TSA excretion rate in } \mathrm{mg} / \mathrm{kg} / \mathrm{h} \text { after } \\
72 \mathrm{~h} \text { oral dosing }\end{array}$ & 0.03126 & 0.0071 & 4.4109 & $>0.20$ & $>0.5$ \\
\hline$F_{0.05,(2), 6,5}=6.98^{\| \prime}$ & & & & & \\
\hline
\end{tabular}

$* n_{\mathrm{DZ}}$, six pairs of fraternal twins.

$\$ n_{\text {MZ, }}$, seven pairs of identical twins.

$\$ F=$ within $\mathrm{DZ}$ mean square/within MZ mean square.

"For $P=0.05$, the initial value of $F$ is 6.98 , comparing seven pairs of identical twins with six pairs of fraternal twins, using a 2-tailed analysis.

the differences between the acute and plateau SU excretion rates may relate to variations in absorption kinetics, since the acute study involved an i.v. dose and the multiple-dose study involved oral doses.

When examining the serum salicylate levels achieved in these young healthy subjects, it was found that the mean serum salicylates ranged from 11.9 to $36.4 \mathrm{mg} / \mathrm{dl}$ after $65-\mathrm{mg} / \mathrm{kg}$ per day dosing for 3 days. This range is appreciably less than the range previously reported in rheumatoid arthritis patients (7). The difference between that study and the present one suggests the possibility that disease state and/or

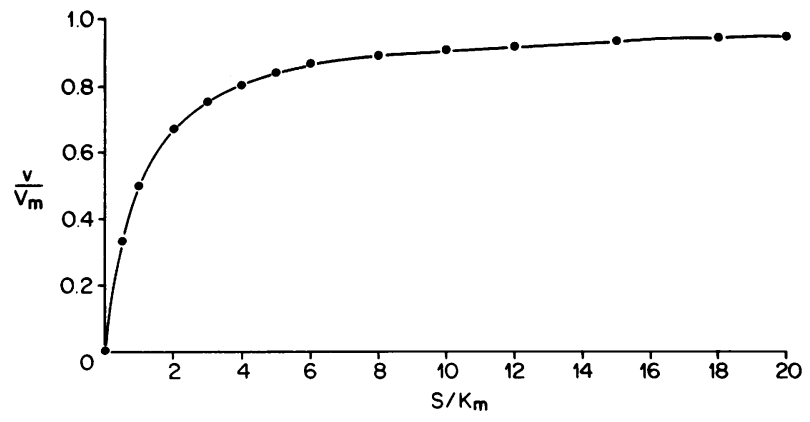

FIGURE 3 Mathematically derived plot of $\nu / V_{m}$ vs. $S / K_{m}$. age may also play a role in determining individual salicylate levels, in addition to the hereditary factors seen in these young, healthy individuals.

The individual twins of three identical pairs and four fraternal pairs lived apart, in different households. Environmental influences were, therefore, similarly randomized for the sets of identical and fraternal twins. Although not rigidly controlled, we feel the equal distribution of environmental differences minimizes bias contributed by this factor.

This study documents a genetic influence on the control of salicylate metabolism and suggests that salicylurate formation is inducible.

\section{APPENDIX A}

The Michaelis-Menton equation is:

$$
\nu=\frac{V_{m} S}{K_{m}+S},
$$

where $\nu=$ observed velocity; $V_{m}=$ maximum velocity; $K_{m}$ $=$ Michaelis-Menton constant; and $S=$ amount in body (as in ref. 10). Divide by $V_{m}$ :

$$
\frac{\nu}{V_{m}}=\frac{S}{K_{m}+S},
$$


multiply the right side by $K_{m} / K_{m}$ :

$$
\frac{\nu}{V_{m}}=\frac{S / K_{m}}{1+S / K_{m}} \text {. }
$$

A graph of $\nu / V_{m}$ vs. $S / K_{m}$ from the above equation is seen in Fig. 3.

From Table III: $\nu=$ mean observed maximum SU excretion rate: $58 \mathrm{mg} / \mathrm{h} ; V_{m}=$ mean $V_{m}: 65.6 \mathrm{mg} / \mathrm{h}$ :

$$
\frac{\nu}{V_{m}}=0.884 \text {. }
$$

From Fig. 3 it is seen that this value is on the flat part of the curve (i.e. approaching $V_{m}$ ) where changes in $S$ using a $K_{m}=338$ (from ref. 10), we find a mean $S=2,231 \mathrm{mg}$.

If the dose given during the second portion of this study is 44.4\% higher than the i.v. dose, then

$$
S^{\prime}=1.444 \times 2,231=3,221 \mathrm{mg} .
$$

Since:

$$
K_{m}=338
$$

then

$$
\frac{S^{\prime}}{K_{m}}=9.53
$$

Again returning to Fig. 3,

$$
\text { for } \begin{aligned}
\frac{S^{\prime}}{K_{m}} & =9.53, \\
\frac{V^{\prime}}{V_{m}} & =0.91 .
\end{aligned}
$$

Since $V_{m}=65.6, \nu^{\prime}=65.6 \times 0.91=59.7 \mathrm{mg} / \mathrm{h}$ (predicted).

This is the predicted SU excretion rate, at steady state, for a $44.4 \%$ increase in dose from $2,231 \mathrm{mg}$. In our study we were not at steady state yet, so our predicted change would be less than this. Nevertheless we used the steady-state predicted value described above to be conservative in our interpretation.

\section{ACKNOWLEDGMENTS}

We are grateful to Edmund Sarkissian for his excellent technical assistance; to Thomas Tozer, Ph.D., and Sidney Riegelman, Ph.D. for their suggestions; and to the University of California at Los Angeles Clinical Research Center for the use of their facilities.

This research was supported in part by U. S. Public Health Service grants GM 15759 and RR-865.

\section{REFERENCES}

1. Done, A. K. 1968. Treatment of salicylate poisoning: review of personal and published experiences. Clin. Toxicol. 1: 451-467.

2. Craig, J. O., I. C. Ferguson and J. Syme. 1966. Infants, toddlers, and aspirin. Br. Med.J. 1:757-761.

3. Evans, D. A. P., and C. A. Clarke. 1961. Pharmacogenetics. Br. Med. Bull. 17: 232-240.

4. Levy, G., and B. A. Gagliardi, 1963. Gastrointestinal absorption of aspirin anhydride. J. Pharm. Sci. 52: 730732.
5. Levy, G., and L. E. Hollister. 1964. Variation in rate of salicylate elimination by humans. Br. Med.J. 2: 286-288.

6. Cummings, A. J., B. K. Martin, and R. Renton. 1966. The elimination of salicylic acid in man: serum concentrations and urinary excretion rates. Br.J. Pharmacol. 26: 461-467.

7. Paulus, H. E., M. Siegel, E. Mongan, R. Okun, and J. J. Calabro. 1971. Variations in serum concentrations and half-life of salicylate in patients with rheumatoid arthritis. Arthritis Rheum. 14: 527-532.

8. Levy, G. 1965. Pharmacokinetics of salicylate elimination in man. J. Pharm. Sci. 54: 959-967.

9. Levy, G., A. W. Vogel, and L. P. Amsel. 1969. Capacitylimited salicylurate formation during prolonged administration of aspirin to healthy human subjects. J. Pharm. Sci. 58: 503-504.

10. Levy, G., and T. Tsuchiya. 1972. Salicylate accumulation kinetics in man. N. Engl. J. Med. 287: 430-432.

11. Levy, G., T. Tsuchiya, and L. P. Amsel. 1972. Limited capacity for salicyl phenolic glucuronide formation and its effect on the kinetics of salicylurate elimination in man. Clin. Pharmacol. Ther. 13: 258-268.

12. Bedford, C., A. J. Cummings, and B. K. Martin. 1965. A kinetic study of the elimination of salicylate in man. $\mathrm{Br}$. J. Pharmacol. Chemother. 24: 418-431.

13. Levy, G., and J. R. Leonards. 1971. Urine pH and salicylate therapy. J. Am. Med. Assoc. 217: 81.

14. Stevenson, G. W. 1960. Rapid ultraviolet spectrophotometric determination of salicylate in blood. Anal. Chem. 32: $1522-1525$.

15. Levy, G., and J. A. Procknal. 1968. Drug biotiansformation interactions in man. I. Mutual inhibition in glucuronide formation of salicylic acid and salicylamide in man. J. Pharm. Sci. 57: 1330-1335.

16. Dowd, J. E., and D. S. Riggs. 1965. A comparison of estimates of Michaelis-Menton kinetic constants from various linear transformations. J. Biol. Chem. 240: 863869.

17. Kempthorne, O., and R. H. Osborne. 1961. The interpretation of twin data. Am. J. Hum. Genet. 13: 320-339.

18. Osborne, R. H., and F. V. De George. 1959. Genetic Basis of Morphological Variation; an Evaluation and Application of the Twin Study Method. Harvard University Press, Cambridge, Mass. 17, 60, 62.

19. Knowler, W. C., and P. H. Bennett and rebuttal by Schur, P. H., C. B. Carpenter, J. S. Stillman, and O. J. Gibson. 1975. HL- AW27 and juvenile rheumatoid arthritis (letter). N. Engl. J. Med. 293: 1323.

20. Vesell, E. S., and J. G. Page. 1968. Genetic control of drug levels in man: antipyrine. Science (Wash. D. C.). 161: 72-73.

21. Vesell, E. S., and J. G. Page. 1969. Genetic control of phenobarbital-induced shortening of plasma antipyrine half-lives in man. J. Clin. Invest. 48: 2202-2209.

22. Vesell, E. S., J. G. Page, and S. Passananti. 1971. Genetic and environmental factors affecting ethanol metabolism in man. Clin. Pharmacol. Ther. 12: 192-201.

23. Vesell, E. S., and J. G. Page. 1968. Genetic control of drug levels in man: phenylbutazone. Science (Wash. D. C.). 159: 1479-1480.

24. Vesell, E. S., and J. G. Page. 1968. Genetic control of dicumarol levels in man. J. Clin. Invest. 47: 2657-2663.

25. Alexanderson, B., D. A. Price-Evans, and F. Sjöquist. 1969. Steady-state plasma levels of nortriptyline in twins: influence of genetic factors and drug therapy. $\mathrm{Br}$. Med. J. 4: 764-768.

26. Bönicke, R., and B. P. Lisboa. 1957. Uber die Erbbedingtheit der intraindividuellen Konstanz der isoniazidaus- 
scheidung beim Menschen (Untersuchungen an eineiigen und Zweieiigen Zwillingen). Naturwissen. schaften. 44: 314-316.

27. Neel, J. V., and W. J. Schull. 1954. Human Heredity. University of Chicago Press, Chicago, Ill. 273-275.

28. Zar, J. H. 1974. Biostatistical Analysis. Prentice-Hall, Inc., Englewood Cliffs, N. J. 103.

29. Douglas, J. F., B. J. Ludwig, and N. Smith. 1963. Studies on the metabolism of meprobamate. Proc. Soc. Exp. Biol. Med. 112: 436-438.
30. Conney, A. H. 1967. Pharmacological implications of microsomal enzyme induction. Pharmacol. Rev. 19: 317366.

31. Müller, F. O., H. K. L. Hundt, and A. C. de Kock. 1975. Decreased steady-state salicylic acid plasma levels associated with chronic aspirin ingestion. Curr. Med. Res. Opinion. 3: 417-422.

32. Vesell, E. S. 1968. Genetic and environmental factors affecting hexobarbital metabolism in mice. Ann. N. Y. Acad. Sci. 151: 900-912. 